\title{
(6) OPEN ACCESS \\ The role of embedded research in quality improvement: a narrative review
}

\author{
Cecilia Vindrola-Padros, ${ }^{1,2}$ Tom Pape, ${ }^{2,3}$ Martin Utley, ${ }^{3}$ Naomi J Fulop ${ }^{1}$
}

- Additional material is published online only. To view please visit the journal online (http://dx.doi.org/10.1136/bmjqs2015-004877).

1 Department of Applied Health Research, University College London, London, UK

${ }^{2}$ University College London Hospitals NHS Foundation Trust, London, UK

${ }^{3}$ Clinical Operational Research Unit, University College London, London, UK

\section{Correspondence to}

Dr Cecilia Vindrola-Padros, Department of Applied Health Research, University College London, 1-19 Torrington Place, London WC1E 7HB, UK; c.vindrola@ucl.ac.uk

Received 25 September 2015 Revised 30 March 2016 Accepted 9 April 2016 Published Online First 29 April 2016

CrossMark

To cite: Vindrola-Padros $C$, Pape T, Utley $\mathrm{M}$, et al. BMJ Qual Saf 2017;26:70-80.

\section{INTRODUCTION}

The use of research evidence to facilitate improvements in healthcare quality continues to be a topic widely debated by scholars and practitioners. ${ }^{1}{ }^{2}$ The concept of 'knowledge mobilisation' has been developed, with strategies to help bridge this gap. ${ }^{3}$ These strategies include the development of "a culture of partnership between academic researchers and decision-makers to assist in strengthening the development of policy, practice and social innovation, or the co-production of knowledge". ${ }^{3} 4$ It is based on the premise that knowledge that is collected and created 'on the ground', through daily interaction and negotiation with practitioners, managers and service users, ${ }^{4}$ will provide better insight into the issues affecting these stakeholders, be more relevant to the local context and will, therefore, be more easily incorporated into changes in practice. ${ }^{5-11}$

Different strategies have been used internationally to promote knowledge coproduction. $^{12}$ Several of these strategies entail the creation of partnerships between academic and healthcare organisations. ${ }^{13-19}$ In some cases, these partnerships use 'boundary spanners', ${ }^{19} 20$ 'knowledge brokers' ${ }^{21}$ or other intermediary roles, ${ }^{5}$ where individuals work to link practitioners with knowledge and develop organisational capacity to carry out and incorporate research into practice. ${ }^{18} 22$ One type of intermediary role is the embedded researcher. There are multiple definitions of embedded research and one of the goals of this review is to explore the wide range of meanings associated with this term. However, as a starting point, we used the definition proposed by McGinity and Salokangas, ${ }^{23}$ where embedded researchers are defined as those who work inside host organisations as members of staff, while also maintaining an affiliation with an academic institution. Their task is seen as collaborating with teams within the organisation to identify, design and conduct research studies and share findings which respond to the needs of the organisation, and accord with the organisation's unique context and culture. ${ }^{23}$ The role of embedded researchers differs from that of knowledge brokers and boundary spanners. Embedded researchers may use techniques used by knowledge brokers such as knowledge management, linkage and exchange and capacity building (based on the definition of knowledge broker used by ${ }^{5}{ }^{6}{ }^{21}$ ). Furthermore, they might operate as 'boundary spanners' in the sense that they work across organisational boundaries. ${ }^{5}$ However, their main purpose is to carry out research, to coproduce knowledge. The research is therefore produced through a collaborative and participative process, and it is jointly 'owned'. ${ }^{23}$

The use of embedded researchers within and outside of healthcare appears to be a growing practice, ${ }^{14}$ but, to our knowledge, there are no published reviews of the characteristics of this approach, its potential role and the challenges it might face. Therefore, this review addresses the following questions. What are the characteristics of embedded research? What is the potential role for embedded researchers to facilitate improvement research that makes a difference? What are the challenges of such models? How can the lessons learned by embedded researchers in other sectors be applied to embedded research in healthcare? Our review synthesises the available literature on the experiences of researchers using the embedded research approach and presents a series of lessons learned for its application to research aimed at quality improvement in healthcare. 


\section{METHODS}

We carried out a narrative review ${ }^{24-26}$ to explore the role that embedded researchers could play in improvement efforts in healthcare. We conducted a two-stage bibliographic search of publications in English from 1937 to November 2015 using MEDLINE, Web of Science, PsychInfo, ProQuest Social Science and CINAHL Plus. In the first stage, we used the following search terms: 'embedded research' OR 'embedded researcher' OR 'embedded researchers' OR 'researcher-in-residence' OR 'researcher in residence' OR 'boundary spanners' OR 'boundary spanner'. We included 'boundary spanner' as a search term to account for the work of researchers working across multiple organisations as this was an important aspect of the definition of embedded research we used as a starting point. ${ }^{23}$ Due to the contested nature of the definition of embedded research, we carried out a second stage of the search based on the identification of terms used in the articles that we included in the first stage of the review. These terms were: 'intermediaries' OR 'transient government officials' OR 'embedded scientist' OR 'engaged scholar' OR 'knowledge broker'. In the same way, we iterated our search terms in this two-stage process, we also applied the working definition of embedded research outlined above flexibly in order to capture the wide range of approaches being employed in this emerging field (see under 'Defining embedded research' in Results section).

We conducted a review of bibliographies to identify further relevant publications and hand-searched the following journals: BMJ, BMJ Quality and Safety, Anthropology in Action, BMC Health Services Research and Implementation Science. These journals were selected based on our findings of the initial searches. Results were combined into RefWorks, and duplicates were removed.

The inclusion criteria were peer-reviewed journal articles focused on the embedded research approach both within and outside healthcare. The latter was included because the reflections on the process of carrying out research as part of an organisation in other sectors may be valuable for healthcare research. We excluded publications that were published in languages other than English.

The exclusion criteria are presented in figure 1 . The included articles were analysed using a data extraction form developed in RedCap (Research Electronic Data Capture), which was created after the initial screening of full-text ${ }^{27}$ articles (see online supplementary appendix 1). We analysed the content of the articles in relation to the questions set out above. In addition, we captured themes emerging from the articles to include relevant issues not covered by our initial research questions.

\section{RESULTS}

The first search yielded 360 published articles (see figure 1). The articles were screened in RefWorks by two of the authors (CV-P and TP) based on title, language, general topic, and type of publication, resulting in a total of 154 articles. Screening based on abstracts resulted in 38 articles for full-text review. The review of bibliographies yielded six more articles. The second search yielded 4173 articles; initial screening based on title led to 70 articles. Screening based on abstracts resulted in 20 articles for full-text review (see figure 1). The number of articles included for full-text review from both search stages was 64 . After the full-text review, 47 articles were excluded. Seventeen articles were included in the final selection.

Our review of the literature indicates that the embedded research approach is an emerging trend within and beyond healthcare. Table 1 contains a description of the publications included in the review. The review contains eight healthcare-related publications and nine non-healthcare-related publications.

\section{Defining embedded research}

There is currently a wide spectrum of research activities that share characteristics that embody 'embedded research'. While our working definition included a requirement that embedded researchers need to have dual affiliation (to an academic institution and the host organisation), ${ }^{23}$ we found that five of the articles included in the review did not discuss issues of dual affiliation. These articles, however, satisfied all of the other characteristics outlined in our working definition. One additional article clearly stated that the researchers were not affiliated to an academic institution while they were embedded. We included this article because the authors reflect on the positive and negative aspects of not having this dual affiliation. The approach we envision as embedded research is still in early stages of development, but despite variations in the affiliation of researchers, a series of common features can be identified (see box 1).

\section{Becoming part of the organisation}

Lewis and Russell ${ }^{37}$ regard it as essential that the researcher undergoes a process of immersion within his or her host organisation. By 'being there,' the researcher is able to grasp the challenges faced by the organisation, its goals and interests and the contexts where these play out. ${ }^{23} 3637$

One of the main challenges of improving the quality of healthcare is the development of an organisational culture that is supportive and committed to improvement. ${ }^{1}$ As Dixon-Woods et $a l^{1}$ have argued, "problems can occur when improvement efforts run counter to centrally driven national pushes and pressures or are introduced into environments already suffering organisational stress from mandated requirements". By being immersed in the organisation, the embedded researcher can gain greater understanding of the pressures and problems faced at different 


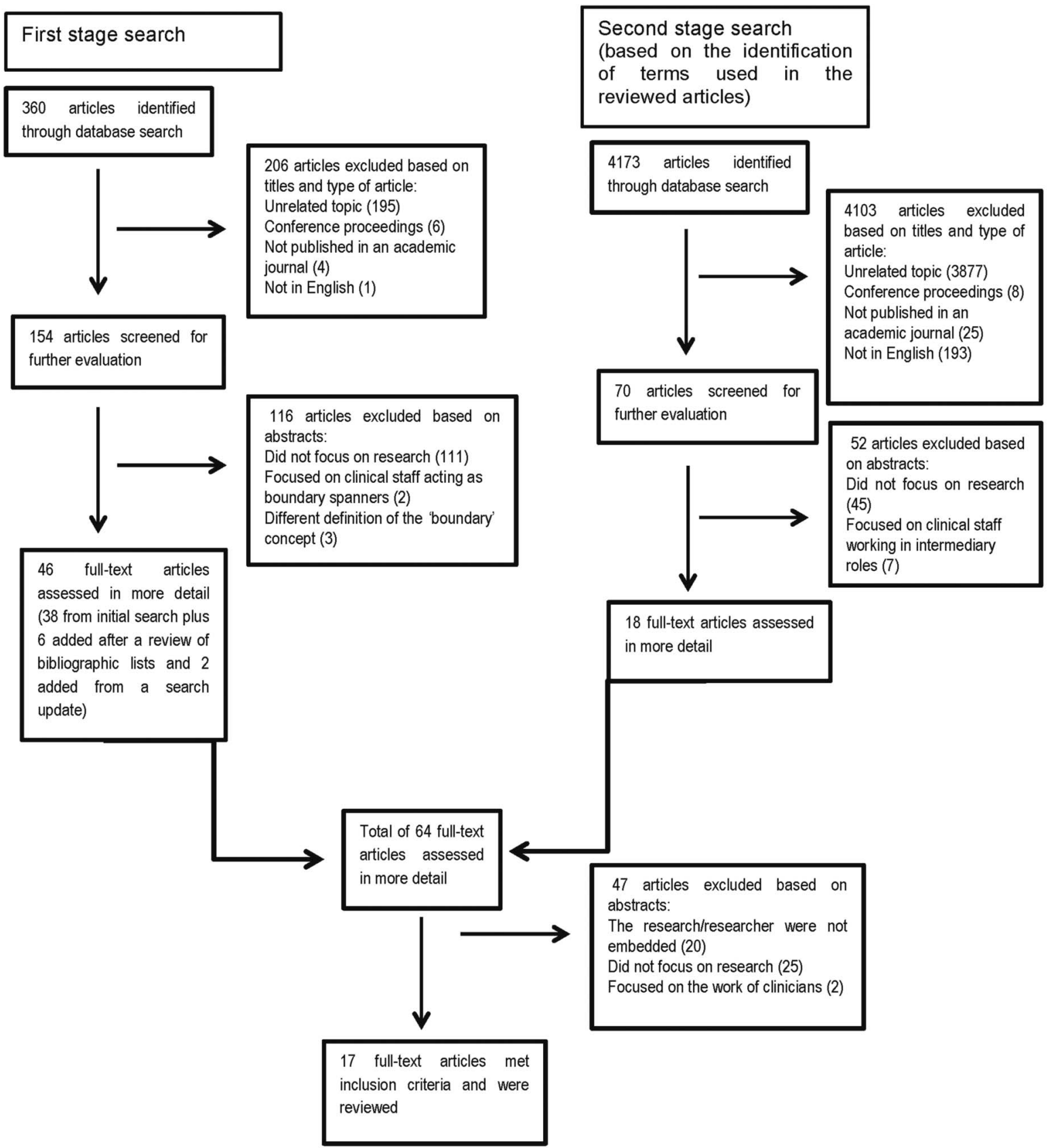

Figure 1 Flow diagram of publication selection process.

levels of the organisation and tailor improvement strategies accordingly. ${ }^{1423}$

\section{Developing relationships with staff}

Physical presence alone is not enough to become an embedded researcher. As Wong ${ }^{34}$ highlights, an important component of 'embeddedness' lies in the quality and types of relationships the researchers foster with staff. Through these relationships, the researchers gain trust and are seen as members of the team. $^{29} 3439$ Their positionality, or the way researchers see themselves and are seen by others in the organisation, varies in relation to the people involved and the context. $^{37}$ In his embedded work, Duggan ${ }^{39}$ established different collaborative relationships, such as: 'critical friendship' (working in equal relation to the project manager), 'critical nephewship' (working in a junior position) and 'critical orphanship' (unattached to the project team). These relationships allowed him to reach out and capture the views of staff at different levels of management, acting as an equal with some staff and in a more subordinate position with others. When acting as an 'unattached' researcher, he had more flexibility to participate in new activities within the organisation.

Establishing collaborative relationships with local teams is important for uncovering the different viewpoints of staff members regarding the issues faced by 
Table 1 Characteristics of the articles included in the review and definition of embedded research/researcher

\begin{tabular}{|c|c|c|c|c|c|c|c|}
\hline Article & Country & Year & Sector & $\begin{array}{l}\text { Definition of embedded research/ } \\
\text { researcher }\end{array}$ & $\begin{array}{l}\text { Characteristics of the } \\
\text { embedded researcher/ } \\
\text { researchers }\end{array}$ & Perceived benefits & Perceived challenges \\
\hline $\begin{array}{l}\text { Groundwater-Smith } \\
\text { and Mockler }{ }^{28}\end{array}$ & Australia & 2002 & Education & $\begin{array}{l}\text { "Researcher in Residence is a phrase used to } \\
\text { connote a role analogous to a 'writer in } \\
\text { residence' or 'artist in residence'. However, it } \\
\text { is a positioning which is distinctive from being } \\
\text { a resident in the fullest sense of the term, in } \\
\text { that the researcher maintains her affiliation } \\
\text { with her university and broader educational } \\
\text { research and professional development } \\
\text { consultancy". } 28\end{array}$ & $\begin{array}{l}\text { Researcher has relative autonomy } \\
\text { in the host organisation. }\end{array}$ & $\begin{array}{l}\text { If the embedded position is } \\
\text { funded by the host } \\
\text { organisation, it allows the } \\
\text { researcher to develop long-term } \\
\text { relationships with staff and } \\
\text { guarantee the sustainability of } \\
\text { the research. }\end{array}$ & $\begin{array}{l}\text { The researcher might face difficulties } \\
\text { understanding and navigating the } \\
\text { terrain of the host organisation, and } \\
\text { thus be seen permanently as an } \\
\text { 'outsider.' }\end{array}$ \\
\hline Reiter-Theil $^{29}$ & Switzerland & 2004 & Health & $\begin{array}{l}\text { Researchers carrying out research in the } \\
\text { relevant context without performing the same } \\
\text { practices as those studied. }\end{array}$ & $\begin{array}{l}\text { Carried out observations and } \\
\text { documented clinical practice. } \\
\text { Acted as 'some kind of team } \\
\text { member.' }\end{array}$ & $\begin{array}{l}\text { Provided valid and meaningful } \\
\text { results to practice. } \\
\text { Allowed researchers to ask the } \\
\text { 'right' questions. }\end{array}$ & $\begin{array}{l}\text { Effort required to maintain trust, } \\
\text { reliability and stamina among } \\
\text { clinicians and research team. }\end{array}$ \\
\hline Hentschel et $\left.a\right|^{30}$ & $\begin{array}{l}\text { Germany/ } \\
\text { Switzerland }\end{array}$ & 2006 & Health & $\begin{array}{l}\text { "Method of the embedded researcher [...] } \\
\text { allows for a combination of methods of } \\
\text { systematic observation and case } \\
\text { documentation in a naturalistic setting". }{ }^{30}\end{array}$ & $\begin{array}{l}\text { Carried out observations and } \\
\text { documented clinical practice. } \\
\text { Used the embedded research } \\
\text { method outlined in. }{ }^{29}\end{array}$ & Not specified & Not specified \\
\hline Pyett et $\left.a\right|^{\beta 1}$ & Australia & 2008 & Health & $\begin{array}{l}\text { Three researchers-in-residence employed by an } \\
\text { aboriginal community-controlled health } \\
\text { organisation. Two of the researchers are also } \\
\text { affiliated to a university. }\end{array}$ & - & - & - \\
\hline Nutley et $\left.a\right|^{32}$ & UK & 2008 & Education & $\begin{array}{l}\text { "Interactive relationship between researchers, } \\
\text { managers, and practitioners in the } \\
\text { development of research-based guidance, } \\
\text { protocols, and tools". }{ }^{32}\end{array}$ & $\begin{array}{l}\text { Based on the translation of } \\
\text { research into practice by individuals } \\
\text { in local policy or management } \\
\text { roles. } \\
\text { Research becomes embedded in } \\
\text { systems, processes and standards. }\end{array}$ & $\begin{array}{l}\text { Model may be suited to staff in } \\
\text { certain circumstances and where } \\
\text { practice tools can be tailored to } \\
\text { the local context. }\end{array}$ & $\begin{array}{l}\text { Embedded research model needs to } \\
\text { adapt to the particular research } \\
\text { questions that need to be addressed. }\end{array}$ \\
\hline Jenness $s^{33}$ & USA & 2008 & $\begin{array}{l}\text { Judicial } \\
\text { system }\end{array}$ & $\begin{array}{l}\text { "I use the term embedded researcher to talk } \\
\text { about something }[\ldots . .] \text { that provides multiple } \\
\text { vantage points from which to view the scene: } \\
\text { occupying multiple locations within and under } \\
\text { the control of a single field of play while also } \\
\text { moving from one site to another, one level of } \\
\text { analysis to another, and one constituency to } \\
\text { another-ultimately having a presence as a } \\
\text { didactic participant throughout a field of } \\
\text { play". }\end{array}$ & $\begin{array}{l}\text { Worked as 'a public servant.' } \\
\text { Carried out in-depth fieldwork with } \\
\text { inmates and wardens in the } \\
\text { California prison system. }\end{array}$ & $\begin{array}{l}\text { A good way to get a unique } \\
\text { perspective, insight and data. }\end{array}$ & $\begin{array}{l}\text { The researcher has relations of } \\
\text { dependence with the host } \\
\text { organisation, which might shape the } \\
\text { type of research that is conducted and } \\
\text { the dissemination of findings. }\end{array}$ \\
\hline
\end{tabular}




\begin{tabular}{|c|c|c|c|c|}
\hline Article & Country & Year & Sector & $\begin{array}{l}\text { Definition of embedded research/ } \\
\text { researcher }\end{array}$ \\
\hline$\overline{\text { Wong }^{34}}$ & Australia & 2009 & Education & $\begin{array}{l}\text { Researcher employed full-time to conduct } \\
\text { research within an organisation. }\end{array}$ \\
\hline Nutley et $a l^{35}$ & UK & 2009 & $\begin{array}{l}\text { Social } \\
\text { care }\end{array}$ & $\begin{array}{l}\text { "Research enters practice indirectly; it } \\
\text { becomes embedded in systems, processes and } \\
\text { standards. [...] Research knowledge is } \\
\text { translated into frontline practice activities by } \\
\text { intermediaries". }\end{array}$ \\
\hline $\begin{array}{l}\text { Hackett and } \\
\text { Rhoten }^{36}\end{array}$ & USA & 2011 & $\begin{array}{l}\text { Science } \\
\text { policy }\end{array}$ & $\begin{array}{l}\text { Two researchers worked as transient } \\
\text { government officials at the National Science } \\
\text { Foundation (NSF) "with responsibility to } \\
\text { manage a research program, direct a division, } \\
\text { develop new research solicitations, serve on } \\
\text { NSF policy committees, and conduct our } \\
\text { research" }{ }^{36}\end{array}$ \\
\hline
\end{tabular}

Characteristics of the

embedded researcher/ researchers

Perceived benefits

Perceived challenges

Worked alongside, shared office

space and socialised with

Increased local staff members' practitioners.

capacity to conduct research. Contributed to the continuous

Embedded researchers participated improvement of programme

in six studies focused on

delivery.

programme evaluations (outcomes

and processes) and research projects addressing questions that arose from practice and/or the

local staff the

literature.

One of the goals was also to

increase staff engagement with

research.

Translation of research-insights into Model may be suited to staff in practice activities.

opportunity to reflect on their work, increase their skills and knowledge, and collaborate

with other staff members.

Increased the organisation's

capacity to inform policy and practice.

certain circumstances and where practice tools can be tailored to the local context.

Managed a research programme and carried out research. Developed new research solicitations.

Served on internal committees.

Guarantees the researchers' access to staff members and provides the opportunity for witnessing internal events and processes.

Allows the researchers to engage in discussion and reflection with members of the organisation.

Allows researchers to engage with real problems in a real

context.

Lewis and Russell ${ }^{37} \quad$ UK 2011 Health "A situationally appropriate way of 'doing

Researcher acts as 'some kind of ethnography' that is founded on the principles team member.

and practice of immersion fieldwork while

Researcher maintains a

Enables researchers to respond to collaborators' needs and being responsive to working with reflexive collaborators, adaptive to the requirements of ethics and other forms of research regulation, and accommodating to audiences eager for new forms of ethnographic output".

collaborative relationship with

expectations.

Not all researchers are suitable for embedded roles; personal characteristics and dispositions play an important role.

There needs to be a 'good fit'

between the researcher and the organisation.

Sharing of findings might be restricted if the organisation owns the intellectual property.

Embedded research model needs to adapt to the particular research

questions that need to be addressed.

Researchers might face restrictions in the dissemination of findings. Researchers occupy an intermediate status with commitments to often conflicting values.

Requires a certain critical distance. Researchers must deal with working in a state of 'in-between-ness.'

The researcher has access to a wide range of people and informal practices, increasing the depth and diversity of
Ethical regulation procedures cannot always be adapted to the realities and timeframes of embedded research. The researcher establishes 


\begin{tabular}{|c|c|c|c|c|c|c|c|}
\hline Article & Country & Year & Sector & $\begin{array}{l}\text { Definition of embedded research/ } \\
\text { researcher }\end{array}$ & $\begin{array}{l}\text { Characteristics of the } \\
\text { embedded researcher/ } \\
\text { researchers }\end{array}$ & Perceived benefits & Perceived challenges \\
\hline & & & & $\begin{array}{l}\text { by staff status or membership with the } \\
\text { purpose of identifying and implementing a } \\
\text { collaborative research agenda". }{ }^{23}\end{array}$ & $\begin{array}{l}\text { develop trusting relationships. } \\
\text { Attended and participated in } \\
\text { steering board meetings. } \\
\text { Developed reports sharing research } \\
\text { findings. }\end{array}$ & $\begin{array}{l}\text { collected data. } \\
\text { The research can respond in an } \\
\text { ad hoc way to data collection } \\
\text { opportunities. } \\
\text { Insider knowledge allows the } \\
\text { researcher to tailor the research } \\
\text { to meet the needs of the } \\
\text { organisation. }\end{array}$ & $\begin{array}{l}\text { commitments with multiple subgroups } \\
\text { within the organisation which can } \\
\text { sometimes come into conflict. } \\
\text { The researcher operates in a state of } \\
\text { 'in-between-ness' between the } \\
\text { organisation and university. }\end{array}$ \\
\hline Marshall et $a l^{14}$ & UK & 2014 & Health & $\begin{array}{l}\text { Researcher is a core member of the delivery } \\
\text { team, with a sense of shared responsibility for } \\
\text { the success or failure of an improvement } \\
\text { initiative. }\end{array}$ & $\begin{array}{l}\text { Researcher establishes trusting } \\
\text { relationships with staff. } \\
\text { Researcher considers their expertise } \\
\text { to be complementary to that of } \\
\text { other team members. }\end{array}$ & $\begin{array}{l}\text { The embedded research } \\
\text { approach addresses the barriers } \\
\text { between researchers and } \\
\text { practitioners, leading to the } \\
\text { negotiation of knowledge and } \\
\text { increasing the chances it will be } \\
\text { used in practice. }\end{array}$ & $\begin{array}{l}\text { Embedded researchers are subjected } \\
\text { to different requirements for career } \\
\text { development in the academic and } \\
\text { health organisations, which are not } \\
\text { always compatible.Research findings } \\
\text { might conflict with organisational } \\
\text { goals. } \\
\text { Further development and evaluation of } \\
\text { the approach are required. }\end{array}$ \\
\hline Marshall ${ }^{3}$ & UK & 2014 & Health & $\begin{array}{l}\text { "Researchers-in-Residence blur the traditional } \\
\text { boundary between their expertise and that of } \\
\text { the health service team by becoming an } \\
\text { integral part of the team rather than central } \\
\text { commentators". }\end{array}$ & $\begin{array}{l}\text { The researchers are in close } \\
\text { connection to routine practice and } \\
\text { produce transferrable knowledge. }\end{array}$ & $\begin{array}{l}\text { The researcher brought unique } \\
\text { expertise to the team and } \\
\text { created new evidence in } \\
\text { collaborative form. }\end{array}$ & $\begin{array}{l}\text { Embedded research might not be } \\
\text { considered valuable under the reward } \\
\text { systems used in most academic } \\
\text { institutions. } \\
\text { Embedded approaches might put } \\
\text { scientific objectivity at risk. }\end{array}$ \\
\hline Marshall ${ }^{39}$ & UK & 2014 & Health & $\begin{array}{l}\text { "An integrated member of a service-based } \\
\text { improvement team". }{ }^{38}\end{array}$ & $\begin{array}{l}\text { Negotiate their knowledge and } \\
\text { integrate it with the expertise of } \\
\text { practitioners. } \\
\text { Researcher interprets research } \\
\text { evidence in relation to the local } \\
\text { context. } \\
\text { Evaluates improvement efforts } \\
\text { looking at the intended and } \\
\text { unintended consequences of } \\
\text { interventions. }\end{array}$ & $\begin{array}{l}\text { Encourages researchers to be } \\
\text { more useful to practitioners. } \\
\text { Encourages practitioners to be } \\
\text { responsive to scientific evidence. } \\
\text { Can help deliver better care } \\
\text { with limited resources. }\end{array}$ & $\begin{array}{l}\text { There are no set guidelines on the } \\
\text { required personal skills and level of } \\
\text { experience of the researcher. } \\
\text { Embedded researchers must negotiate } \\
\text { between their sense of ownership over } \\
\text { the work and their independent } \\
\text { evaluation. }\end{array}$ \\
\hline Duggan $^{40}$ & UK & 2014 & Education & $\begin{array}{l}\text { "Individuals or teams who are either } \\
\text { university-based or employed undertaking } \\
\text { explicit research roles within host schools or } \\
\text { other educational organizations, legitimated } \\
\text { by staff status or membership with the } \\
\text { purpose of identifying and implementing a } \\
\text { collaborative research agenda". }{ }^{23}\end{array}$ & $\begin{array}{l}\text { Carried out qualitative research to } \\
\text { collect evidence for a new initiative. } \\
\text { Devised an evaluation framework. } \\
\text { Contributed to funding applications } \\
\text { for internal projects. }\end{array}$ & $\begin{array}{l}\text { Allowed the researcher to gain } \\
\text { insight into daily practice and } \\
\text { the nuances of collaborative } \\
\text { work. }\end{array}$ & $\begin{array}{l}\text { Embedded research can be disrupted } \\
\text { by policy, personnel or organisational } \\
\text { change. }\end{array}$ \\
\hline $\begin{array}{l}\text { McGinity and } \\
\text { Salokangas }\end{array}$ & UK & 2014 & Education & $\begin{array}{l}\text { "Individuals or teams who are either } \\
\text { university-based or employed undertaking } \\
\text { explicit research roles within host schools or }\end{array}$ & $\begin{array}{l}\text { Researchers 'get under the skin' of } \\
\text { organisations in order to document } \\
\text { multiple perspectives and }\end{array}$ & $\begin{array}{l}\text { The researcher obtains greater } \\
\text { access to the organisation, } \\
\text { which facilitates data collection }\end{array}$ & $\begin{array}{l}\text { Embedded research is a complex } \\
\text { practice, influenced by organisational } \\
\text { pressures, interests, and changes. }\end{array}$ \\
\hline
\end{tabular}




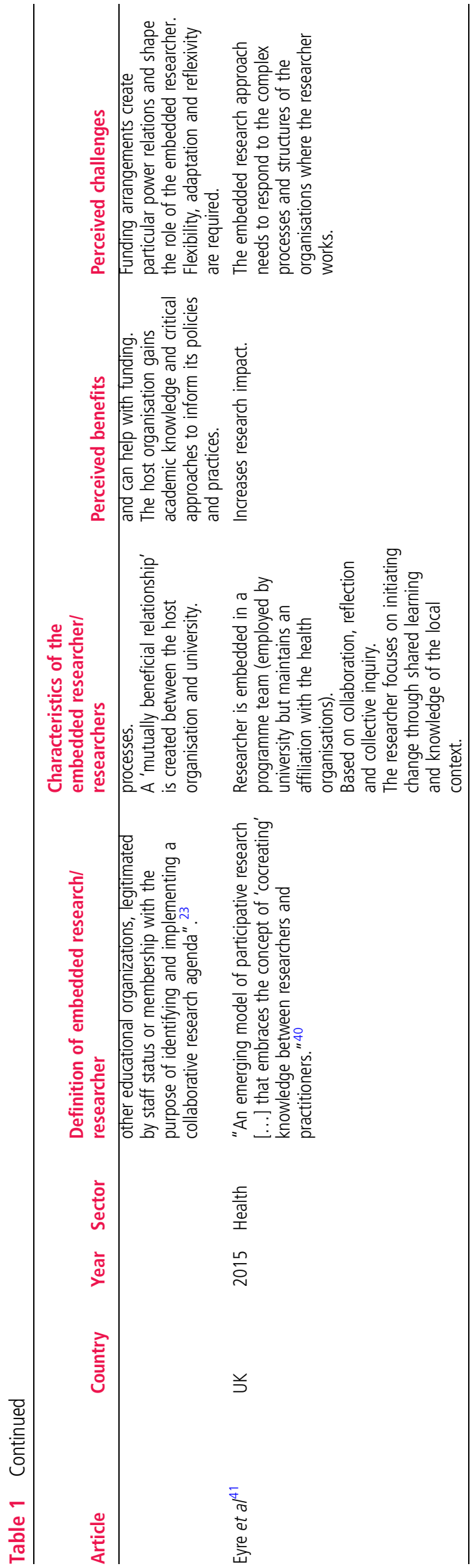

Box 1 Characteristic features of embedded research

1. Researcher is usually affiliated to an academic institution as well as an organisation outside of academia, thus working in a state of 'in-between-ness'.

2. Researcher develops relationships with staff and is seen as part of the team.

3. Researcher generates knowledge in conjunction with local teams (coproduced) which responds to the needs of the host organisation.

4. Researcher builds research capacity in the host organisation.

the organisation and how they could be addressed. This insight into the wide range of perspectives coexisting in the organisation can allow the researcher to make research findings more relevant to local end users, promote ownership of these findings and anticipate potential sources of tension produced by competing views. ${ }^{38}$ Improvement initiatives in healthcare frequently (but by no means always) emerge from the interests of senior groups within organisations who have particular ideas about the problems faced by the organisation, their causes and the best ways to solve them. These initiatives are often developed without the involvement of those who will experience changes in their daily practice and are imposed as a top-down measure. $^{42}$ As a consequence, they often fail. ${ }^{1}$ The spread of innovations can also encounter similar obstacles when it is meant to intersect different groups and cross professional boundaries. ${ }^{43}$

Embedded researchers seek to tackle this issue of top-down approaches by considering the fact that each organisation has multiple subgroups with their own views of how the organisation works and how services should be organised. ${ }^{36}{ }^{37}$ By working with these groups on an ongoing basis, embedded researchers are able to understand the complexity of the situations faced by the organisation and propose strategies that respond to the interests of a wider range of stakeholders. ${ }^{38}$

Critical reflection by the researcher and local team

Some authors argue that the creation of these collaborative relationships can be enriched when the researcher employs a reflexive approach. ${ }^{23} \quad 37 \quad 38$ Reflexivity entails a conscious exercise of thinking about the position the researcher occupies as an individual, and as part of the organisational context. ${ }^{37}$ Reflexivity helps the researcher maintain a clearer idea of their role and capacity to intervene. ${ }^{38}$ It also supports a continuous reassessment and adjustment of the researcher's practice. ${ }^{34}$ When researchers are able to foster individual reflexivity, they become aware of potential barriers to the research process, and can thus adapt research activities to address the needs and 
interests of all involved parties, and create stronger relationships with the people participating in the research project. ${ }^{37} 34$ Furthermore, when shared with other members of the team in the form of collective reflexivity, this exercise provides a way of fostering critical thinking within the team even after the researcher leaves the organisation-a form of capacity building. ${ }^{34}$

\section{Informing practice}

Some have argued that in the traditional model of research, there is a disconnection between 'producers' and 'consumers' of research evidence. ${ }^{3} 44{ }^{45}$ As a consequence, organisational decision-making is not always informed by health service research evidence. ${ }^{3}$ One of the goals of embedded research is the rapid delivery of research findings and their quicker incorporation into improvements in practice. ${ }^{14}$ Due to their immersion within the organisation, embedded researchers can produce research that is more relevant to the 'end user' and can give advice and flag issues in formal and informal ways. ${ }^{37} 34$

Having regular meetings with clinical teams and management groups to discuss progress of their work is proposed as a useful mechanism for the provision of iterative feedback. ${ }^{34}$ Such meetings are about discussing the research progress and maintaining relationships, and also about ensuring that all relevant members of the host organisation still feel they 'own' the problem, and will be willing to own the solution, too. The process of engaging staff to own the problem and support service improvement has been widely discussed in the healthcare quality improvement literature. Dixon-Woods and colleagues have argued that 'soft' and 'hard' tools might be needed to persuade staff to change current practices in healthcare organisations. ${ }^{146}$ Gollop et $a l^{47}$ have indicated that individualised and tailored influencing techniques, such as finding the right 'hook' when making the case for change, might be required to reduce some healthcare professionals' scepticism and resistance to service improvement.

Embedded researchers can use their presence and daily working relationships to implement some of these 'soft persuasive tools'. The researcher might facilitate meetings, provide technical assistance to solve problems and share their knowledge of the research evidence. They might tailor feedback by weaving in the host organisation's own words or letting actors from the host organisation take the lead.

Due to their knowledge of the organisation's context and culture, the researcher is able to share the findings in relation to the wider issues at stake in the organisation, such as the need to scale-up interventions or combine the study with wider improvement initiatives taking place across the organisation. ${ }^{34} 37$ Furthermore, the researcher identifies and describes problems, and also cases of good practice, ${ }^{34}$ thereby helping to empower teams to continue with work that is producing positive outcomes.

\section{Capacity building}

In many cases, embedded researchers help build research capacity so that the benefits of embedded research extend beyond the researcher's direct involvement. Capacity building might include promoting a reflexive culture before launching new initiatives, creating awareness of less well-known ways to approach problems, establishing a research culture, teaching evaluation skills or assisting in applications for external funding. ${ }^{14} 34 \quad 35$ In contrast to other research approaches that tend to be based on the development of individual partnerships between researchers and staff, the embedded approach centres on the incorporation of research into the organisation's systems, processes and practices, thus promoting its sustainability over time. ${ }^{32} 35$

It is argued that embedded research also develops capacity at universities. It provides researchers with the opportunity to test methods and theories in practice-thus enhancing their applicability to real-life circumstances. ${ }^{14} 23 \quad 39$ Furthermore, the experience of working alongside healthcare professionals will help researchers later in their academic careers to design studies that generate insights helpful for healthcare organisations. ${ }^{23} 3336$

\section{The challenges of carrying out embedded research}

Carrying out rigorous research within healthcare organisations is challenging. For instance, some authors mention their hesitation when contemplating designing research that could potentially lead to negative results or highlight undesirable qualities of the host organisation. ${ }^{34}$ When attempting to disseminate findings, researchers might be bound by internal regulations that prevent them from publishing information considered harmful by the host organisation. ${ }^{36}$ The dual affiliation of many embedded researchers places them in a state of 'in-between-ness,' where they have to show their commitment to the organisation's goals and to the academic standards established for conducting publishable research in their fields. ${ }^{37} 38$ This resembles the issues discussed in the literature on intermediary and boundary roles and the presence of role tensions or 'role strain,' a situation created when individuals have to deal with competing demands generated by members of the organisations they are affiliated to. ${ }^{48} 49$

One way to deal with the challenges connected with dual affiliation is to agree on clear guidelines from the beginning to manage expectations. ${ }^{50}$ The guidelines might define the role of the researcher, types of studies they will be able to undertake, study timeframes and feedback processes. ${ }^{14}{ }^{34}$ Other embedded researchers have indicated that even if the researcher does not have an affiliation with an academic 
Box 2 Lessons learned from the use of embedded researchers within and outside of the healthcare sector

1. The embedded researcher needs to consider the experiences and points of view of the different subgroups within the organisation.

2. The creation of collaborative relationships with staff in the local organisation and the coproduction of knowledge can be enriched by practicing 'reflexivity' (reflecting on own position as an individual and as part of the organisational context).

3. Clear guidelines should be agreed between the embedded researcher and the local organisation from the beginning to manage expectations.

4. The researcher should schedule regular meeting with clinical teams and management groups to provide iterative feedback.

5. It is important for embedded researchers to maintain links with academic institutions to preserve a critical perspective.

institution, it is important for him or her to maintain regular dialogue with academics about his or her research. ${ }^{29}{ }^{37}$ A connection with academia allows embedded researchers to keep up to date on new trends, preserve a critical perspective and make sure their research is rigorous. ${ }^{37}$ It has also been recommended that embedded researchers should foster relationships with other researchers doing similar work and share lessons of how to manage day-to-day issues. $^{29}$

This review has highlighted a number of lessons that may be useful for embedded researchers, and these are summarised in box 2 .

\section{Limitations of this review}

This review has a number of limitations. There is a lack of consensus around the terminology used to refer to embedded research. Our search terms and screening process might not have captured all of the relevant articles.

\section{CONCLUSION}

Embedded research has the potential to address some of the main challenges in using research to improve quality in healthcare: understanding organisational culture to focus research appropriately, securing engagement from staff at different levels of the organisation to ensure the findings of research are translated into changes in practice and promoting the sustainability of improvement interventions. ${ }^{1}$ As Gold has argued, "in organisations, take up of ideas often occurs through informal processes". ${ }^{51}$ The continuous presence of embedded researchers in healthcare organisations allows for the creation of these informal processes. The coproduction of knowledge between embedded researchers and local teams can lead to greater 'ownership' of the research findings by the healthcare organisation, and consequently, could lead to a smoother incorporation into changes in practice. The development of the research skills of local teams can help ensure research is viewed favourably and used within the organisation even after the embedded researchers have left.

Embedded research involves its own challenges in terms of dual affiliation, relationship building and sharing of results. Given our focus on the embedded research model as a method of coproducing research knowledge, we believe that maintaining a dual affiliation with health and academic organisations will represent a core component of embedded research. Learning from the experience of embedded researchers in different organisational contexts, and from the organisations they work with, could contribute further to our understanding of this approach. Rigorous evaluation of embedded research initiatives is required, which includes assessing the costs and benefits of embedded research for healthcare organisations.

Contributors CV-P, TP, MU and NJF conceived the idea for the review and participated in the design. CV-P and TP carried out the literature search, review and analysis of the selected publications. CV-P and NJF led on the drafting. All authors contributed substantially to writing the paper and all reviewed and approved the final draft.

Funding This paper presents independent research and was funded by the University College London Hospitals (UCLH)

NHS Foundation Trust through matched funding to the National Institute for Health Research Collaboration for Leadership in Applied Health Research and Care (NIHR CLAHRC) North Thames at Bart's Health NHS Trust.

Competing interests CV-P, NJF, MU and TP report grants from the University College London Hospitals (UCLH) NHS Foundation Trust through match funding to the National Institute for Health Research Collaboration for Leadership in Applied Health Research and Care (NIHR CLAHRC) North Thames during the conduct of the study.

Provenance and peer review Not commissioned; externally peer reviewed.

Open Access This is an Open Access article distributed in accordance with the terms of the Creative Commons Attribution (CC BY 4.0) license, which permits others to distribute, remix, adapt and build upon this work, for commercial use, provided the original work is properly cited. See: http://creativecommons.org/licenses/by/4.0/

\section{REFERENCES}

1 Dixon-Woods M, McNicol S, Martin G. Ten challenges in improving quality in healthcare: lessons from the Health Foundation's programme evaluations and relevant literature. BMJ Qual Saf 2012;21:884.

2 Kreindler SA. What if implementation is not the problem? Exploring the missing links between knowledge and action. Int J Health Plann Manage 2014; doi: 10.1002/hpm.2277

3 Marshall MN. Bridging the ivory towers and the swampy lowlands; increasing the impact of health services research on quality improvement. Int J Qual Health Care 2014;26:1-5. 
4 Bannister J, Hardill I. Knowledge mobilisation and the social sciences: dancing with new partners in an age of austerity. Contempor Soc Sci 2013;8:167-75.

5 Chew S, Armstrong N, Martin G. Institutionalising knowledge brokering as a sustainable knowledge translation solution in healthcare: how can it work in practice? Evid Policy 2013;9:335-51.

6 Ward V, House A, Hamer S. Knowledge brokering: the missing link in the evidence to action chain? Evid Policy 2009;5:267-79.

7 Van de Ven A. Engaged scholarship: a guide for organizational and social research. Oxford, UK: Oxford University Press, 2007.

8 Greenhalgh T, Wieringa S. Is it time to drop the 'knowledge translation' metaphor? A critical literature review. J R Soc Med 2011;104:509.

9 Ferlie E, Crilly T, Jashapara A, et al. Knowledge mobilisation in healthcare: A critical review of health sector and generic management literature. Soc Sci Med 2012;74:1297-304.

10 Graham I, Tetroe J, KT Theories Research Group. Some theoretical underpinnings of knowledge translation. Acad Emerg Med 2007;14:936-41.

11 Rowley E, Morriss R, Currie G, et al. Research into practice: Collaboration for Leadership in Applied Health Research and Care (CLAHRC) for Nottinghamshire, Derbyshire, Lincolnshire (NDL). Implement Sci 2012;7:40-51.

12 Cooksey D. A review of $U K$ health research funding. London: The Stationery Office, 2006.

13 D'Andreta D, Scarbrough H, Evans S. The enactment of knowledge translation: a study of the Collaborations for Leadership in Applied Health Research and Care initiative within the English National Health Service. J Health Serv Res 2013;18(Suppl 3):40-52.

14 Marshall M, Pagel C, French C, et al. Moving improvement research closer to practice: the Researcher-in-Residence model. BMJ Qual Saf 2014;23:801-5.

15 Rowley E. Protocol for a qualitative study exploring the role of 'Diffusion Fellows' in bridging the research to practice gap in Nottinghamshire, Derbyshire and Lincolnshire Collaboration for Leadership in Applied Health Research and Care (CLAHRD-NDL). BMJ Open 2012;2:e00604.

16 Martin G, Ward V, Hendy J, et al. The challenges of evaluating large-scale, multi-partner programmes: the case of NIHR CLAHRCs. Evid Policy 2011;7:489-509.

17 Thomson L, Schneider J, Wright N. Developing communities of practice to support the implementation of research into clinical practice. Leadersh Health Serv 2013;26:20-33.

18 Soper B, Yaqub O, Hinrichs S, et al. CLAHRCs in practice: combined knowledge transfer and exchange strategies, cultural change, and experimentation. J Health Serv Res 2013;18:53-64.

19 Gagliardi AR, Webster F, Brouwers MC, et al. How does context influence collaborative decision-making for health services planning, delivery and evaluation? BMC Health Serv Res 2014;14:545.

20 Ettelt S, Mays N. Health services research in Europe and its use for informing policy. J Health Serv Res Policy 2011;16 (Suppl 2):48-60.

21 Bornbaum CC, Kornas K, Peirson L, et al. Exploring the function and effectiveness of knowledge brokers as facilitators of knowledge translation in health-related settings: a systematic review and thematic analysis. Implement Sci 2015;10:162.
22 Walshe K, Davies H. Health research, development and innovation in England from 1988 to 2013: from research production to knowledge mobilization. J Health Serv Res 2013;18:1-12.

23 McGinity R, Salokangas M. Introduction: "Embedded Research" as an approach into academia for emerging researchers. Manag Educ 2014;28:3-5.

24 Arksey H, O’Malley L. Scoping studies: towards a methodological framework. Int J Soc Res Methodol $2005 ; 8: 19-32$.

25 Kastner M, Tricco AC, Soobiah C, et al. What is the most appropriate knowledge synthesis method to conduct a review? Protocol for a scoping review. BMC Med Res Methodol 2012;12:114.

26 Dixon-Woods M, Agarwal S, Jones D, et al. Synthesizing qualitative and quantitative evidence: a review of possible methods. J Health Serv Res Policy 2005;10:45-53.

27 Harris Paul A. Taylor Robert, Thielke Robert, Jonathon Payne, Gonzalez Nathaniel, Conde Jose G, Research electronic data capture (REDCap) - A metadata-driven methodology and workflow process for providing translational research informatics support, J Biomed Inform 2009 Apr;42(2):377-81.

28 Groundwater-Smith S, Mockler N. The knowledge building school: from the outside in, from the inside out. Change Transform Educ 2002;5:15-24.

29 Reiter-Theil S. Does empirical research make bioethics more relevant? "The embedded researcher" as a methodological approach. Med Health Care Philos 2004;7:17-29.

30 Hentschel R, Lindner K, Krueger M, et al. Restriction of ongoing intensive care in neonates: a prospective study. Pediatrics 2006;118:563-9.

31 Pyett P, Waples-Crowe P, van der Sterren A. Challenging our own practices in Indigenous health promotion and research. Health Promot J Austr 2008;19:179-83.

32 Nutley S, Jung T, Walter I. The many forms of research-informed practice: a framework for mapping diversity. Camb J Educ 2008;19:179-83.

33 Jenness V. Pluto, prisons, and plaintiffs: Notes on systematic back-translation from an embedded researcher. Soc Probl 2008;55:1-22.

34 Wong $\mathrm{S}$. Tales from the frontline: the experiences of early childhood practitioners working with an 'embedded' research team. Eval Program Plann 2009;32:99-108.

35 Nutley S, Walter I, Davies H. Promoting evidence-based practice: models and mechanisms from cross-sector review. Res Soc Work Pract 2009;19:552-9.

36 Hackett EJ, Rhoten DR. Engaged, embedded, enjoined: Science and technology studies in The National Science Foundation. Sci Eng Ethics 2011;17:823-38.

37 Lewis SJ, Russell AJ. Being embedded: A way forward for ethnographic research. Ethnography 2011;12:398-416.

38 Rowley H. Going beyond procedure: engaging with the ethical complexities of being an embedded researcher. Manag Educ 2014;28:19-24.

39 Marshall M. Researchers-in-residence: a solution to the challenge of evidence-informed improvement? Prim Health Care Res Dev 2014;15:337-8.

40 Duggan J. Critical friendship and critical orphanship: embedded research of an English local authority initiative. Manag Educ 2014;28:12-18.

41 Eyre L, George B, Marshall M. Protocol for a process-oriented qualitative evaluation of the Waltham Forest and East London Collaborative (WELC) integrated care pioneer programme 
using the Researcher-in-Residence model. BMJ Open 2015;5: e009567.

42 Currie G, Suhomlinova O. The impact of institutional forces upon knowledge sharing in the UK NHS: The triumph of professional power and the inconsistency of policy. Public Adm 2006;84:1-30.

43 Ferlie E, Fitzgerald L, Wood M, et al. The nonspread of innovations: the mediating role of professionals. Acad Manag J $2005 ; 48: 117-34$.

44 Gibbons M, Limoges C, Nowotny H, et al. The New Production of Knowledge The Dynamics of Science and Research in Contemporary Societies. London: SAGE, 1994.

45 Denis J, Lehoux P, Champagne F. A knowledge utilization perspective on fine-tuning dissemination and contextualizing knowledge. In: Lemieux-Charles L, Champagne F, eds. Using knowledge and evidence in healthcare: multidisciplinary perspectives. Toronto, Canada: University of Toronto Press, 2004:18-40.
46 Martin GP, McKee L, Dixon-Woods M. Beyond metrics? Utilizing 'soft intelligence' for healthcare quality and safety. Soc Sci Med 2015;142:19-26.

47 Gollop R, Whitby E, Buchanan D, et al. Influencing sceptical staff to become supporters of service improvement: a qualitative study of doctors' and managers' views. Qual Saf Health Care 2004;13:108-14.

48 Boardman C, Bozeman B. Role strain in university research centres. J High Educ 2007;78:430-63.

49 Parker J, Crona B. On being all things to all people: Boundary organizations and the contemporary research university. Soc Stud Sci 2012;42:262-89.

50 Brewster L, Aveling EL, Martin GP, et al. The Safer Clinical Systems Phase 2 Core Group Collaboration \& Writing Committee. What to expect when you're evaluating healthcare improvement: a concordat approach to managing collaboration and uncomfortable realities. BMJ Qual Saf 2015;24:318-24.

51 Gold M. Pathways to the use of health services research in policy. Health Serv Res 2009;44:1111-36. 